\title{
Reduction in periventricular haemorrhage in preterm infants
}

\author{
W SZYMONOWICZ, V Y H YU, A WALKER, AND F WILSON \\ Department of Paediatrics and Centre for Early Human Development, Queen Victoria Medical Centre, \\ Monash University, Melbourne, Victoria, Australia
}

SUMMARY Our previous cerebral ultrasound study of antecedents of periventricular haemorrhage in infants weighing $1250 \mathrm{~g}$ or less at birth suggested that neonatal events that caused increased or fluctuating cerebral blood flow lead to periventricular haemorrhage. As the risk period for this type of haemorrhage was the first four days of life strict guidelines were introduced to avoid the previously identified neonatal risk factors. No attempt was made to modify obstetric practice. Over the next two years, although the obstetric risk profile, the frequency and severity of hyaline membrane disease, and the gestation, birth weight, and sex distributions of a similar cohort of infants did not change, the incidence of periventricular haemorrhage decreased significantly from $60 \%$ to $36 \%$. Significant antecedents of haemorrhage similar to those found in the previous study included severe bruising, low arterial:fractional inspiratory oxygen ratio and low packed cell volume on admission, hyaline membrane disease, hypercarbia, and hypoxaemia. Assisted ventilation, pneumothorax, treatment with tubocurarine, and hypotension were no longer significant risk factors for periventricular haemorrhage. A multivariate discriminant analysis correctly predicted haemorrhage in $86 \%$ of the study group when bruising, hypercarbia, hypoxaemia, hyaline membrane disease, and low gestation were considered. These results suggest that changes in neonatal practices can reduce the incidence of periventricular haemorrhage and that drug studies indicating similar reductions in haemorrhage need to be evaluated carefully to ensure that placebo and treated groups are in fact comparable.

The use of serial real time cerebral ultrasonography has allowed antecedents of periventricular haemorrhage to be distinguished from its associates in preterm infants. ${ }^{12}$ At the same time several groups have claimed significant reduction in incidence of periventricular haemorrhage by the use of phenobarbitone, ethamsylate, vitamin $\mathrm{E}$, pancuronium, and fresh frozen plasma. ${ }^{3-9}$ Some of these studies have not scanned the infants before enrolment in the drug study and others have not indicated whether the placebo and treated groups had a similar distribution of antecedents for periventricular haemorrhage, making interpretation of their results difficult. In the present study we determined the incidence and severity of periventricular haemorrhage and its antecedent factors after introducing strict guidelines to avoid the previously identified antecedents of the haemorrhage.

\section{Patients and methods}

All infants admitted to the neonatal intensive care unit at Queen Victoria Medical Centre in the years 1983-84 weighing $1250 \mathrm{~g}$ or less at birth were included in the study. Excluded from the study were three infants with multiple congenital anomalies, two infants with central nervous system anomalies, and two infants who died shortly after admission before a cerebral ultrasound scan ( 20 and 60 minutes of age, respectively). One hundred infants were scanned as soon as possible after birth, eight to 12 hourly until 72 hours of age, daily until one week of age, and weekly thereafter until discharge.

A Toshiba SAL 120 real time linear array scanner with a $5 \mathrm{MHz}$ transducer and an ATL MK 600 real time sector scanner with 5 and $7.5 \mathrm{MHz}$ transducers were used to obtain images in coronal, sagittal, and axial planes as previously described. ${ }^{10}$ Our correlation of ultrasound with necropsy findings for periventricular haemorrhage was over $90 \% .{ }^{11}$ Germinal layer haemorrhage was defined as bleeding into the germinal layer overlying the caudate nucleus, intraventricular haemorrhage as any amount of blood seen in the ventricular system, 
and intracerebral haemorrhage as bleeding into the brain parenchyma. Periventricular leucomalacia with cystic degeneration was also identified on serial scanning.

After antecedents of periventricular haemorrhage had been identified in a cohort of infants $\leqslant 1250 \mathrm{~g}$ born in $1982^{1}$ strict guidelines for neonatal care were introduced in January 1983 in an attempt to decrease the frequency of these risk factors. Resuscitation at delivery included the use of elective intubation and sodium bicarbonate to correct acidosis if the infant was not breathing spontaneously by 3 minutes of age. This was a change from the previous routine when intubation was not performed routinely and when sodium bicarbonate was only occasionally given at 10 minutes of age if regular respirations were not established. Closer attention was given to prevention of hypothermia. On admission, stabilisation within one hour was carried out to achieve $\mathrm{pH}$ over $7 \cdot 30$, arterial carbon dioxide tension $35-45 \mathrm{mmHg}$, arterial oxygen tension $50-80 \mathrm{mmHg}$, and packed cell volume over $45 \%$. This too was different from the previous routine when arterial carbon dioxide tensions of $50-60 \mathrm{mmHg}$ were accepted and when rapid stabilisation and correction of anaemia were not emphasised. Continuous monitoring of transcutaneous oxygen and carbon dioxide tensions was carried out on every infant with hyaline membrane disease where possible for 72-96 hours to allow earlier identification of blood gas instability outside our guidelines (arterial carbon dioxide $35-45 \mathrm{mmHg}$, arterial oxygen $50-80$ $\mathrm{mmHg}$ ) in the second study period. Continuous monitoring of arterial blood pressure was also introduced in the second period. Mean blood pressure was kept over $30 \mathrm{mmHg}$ in infants $<1000 \mathrm{~g}$ and over $35 \mathrm{mmHg}$ in those $1000-1250 \mathrm{~g}$ by the use of volume expansion or dopamine infusion, or both. This was a change from the previous routine when lower mean blood pressure was accepted as long as renal function remained adequate.

Infants with severe hyaline membrane disease were monitored closely for pneumothorax by transillumination every four hours, and when a pneumothorax occurred rapid evacuation of air by needle drainage followed by intercostal catheter insertion was emphasised. All infants had routine contrast echocardiography done around 72 hours of age, and if a patent ductus arteriosus was present indomethacin was used to effect closure. Paralysis with tubocurarine or pancuronium was used if activity of the infant led to blood gas instability or if the peak inspiratory pressure required was over $30 \mathrm{~cm} \mathrm{H}_{2} \mathrm{O}$, or both. Metabolic acidosis was corrected by slow infusion of sodium bicarbonate $2 \cdot 8-4 \cdot 2 \%$ over one to two hours for a base deficit of
$5 \mathrm{mmol} / \mathrm{l}$ or more. Phenobarbitone was used only in infants with seizures. Vitamin E $100 \mathrm{mg} / \mathrm{kg} /$ day orally was started on days 5 to 7 when feeds were tolerated.

All obstetric, intrapartum, and neonatal data were recorded prospectively during the study period. In infants with periventricular haemorrhage neonatal data that preceded the diagnosis of periventricular haemorrhage by no more than 8-12 hours were used for analysis. Sample means and standard deviations were calculated to summarise interval data and frequencies of occurrence to summarise categorical data in the groups with and without haemorrhage. To test the significance of differences between the groups Student's $t$ test, $\chi^{2}$ with Yates's correction, and Fisher's exact test were used as appropriate.

To minimise type 1 and type 2 errors 100 infants were enrolled into the study. The 100 infants (cohort 2 ) from the two year period 1983-84 were compared with the 50 infants (cohort 1) from 1982 before changes in neonatal intensive care. Thirty two obstetric, 14 intrapartum, and 99 neonatal variables were analysed to determine the significant differences and similarities between the cohorts. A multivariate discriminant analysis of antecedents for periventricular haemorrhage was performed for both cohorts 1 and 2 to determine if changes in neonatal care had altered the risk profile for periventricular haemorrhage.

\section{Results}

The two cohorts were comparable in obstetric risk factors (Table 1) and neonatal risk factors for periventricular haemorrhage (Table 2), except for those neonatal variables reflecting deliberate changes in neonatal management (Table 3). There

Table 1 Similarities in obstetric factors between cohorts 1 and 2. Values are No (\%) except for duration of labour

\begin{tabular}{lcc}
\hline & $\begin{array}{l}\text { Cohort I } \\
(n=50)\end{array}$ & $\begin{array}{l}\text { Cohort } 2 \\
(n=100)\end{array}$ \\
\hline $\begin{array}{lcc}\text { Outborn } \\
\text { Transfer in utero }\end{array}$ & $4(8)$ & $12(12)$ \\
& $31(62)$ & $66(66)$ \\
Antepartum haemorrhage & $11(22)$ & $14(14)$ \\
Maternal pre-eclampsia & $10(20)$ & $25(25)$ \\
Rupture of membranes $>24$ hours & $14(28)$ & $18(18)$ \\
Presence of labour & $41(82)$ & $75(75)$ \\
$\begin{array}{l}\text { Mean (SD) duration of labour (hrs) } \\
\text { Abnormal fetal heart rate pattern }\end{array}$ & $6 \cdot 3(5 \cdot 0)$ & $6 \cdot 0(5 \cdot 1)$ \\
& $7(14)$ & $17(17)$ \\
Mode of delivery: & & \\
$\quad$ Vaginal & $32(64)$ & $56(56)$ \\
$\quad \begin{array}{l}\text { Caesarean } \\
\text { Use of forceps }\end{array}$ & $18(36)$ & $44(44)$ \\
\hline
\end{tabular}


were no significant changes in referral patterns or obstetric practice and no changes in the infant population admitted for neonatal intensive care. The significantly higher arterial $\mathrm{pH}$, body temperature, and mean blood pressure on admission and the higher mean blood pressure and lower arterial carbon dioxide tension over the risk period for

Table 2 Similarities in neonatal factors between cohorts 1 and 2

\begin{tabular}{lcc}
\hline & $\begin{array}{l}\text { Cohort I } \\
(n=50)\end{array}$ & $\begin{array}{l}\text { Cohort 2 } \\
(n=100)\end{array}$ \\
\hline Mean (SD) birth weight (g) & $904(205)$ & $949(209)$ \\
Mean (SD) gestation (wks) & $27 \cdot 5(2 \cdot 4)$ & $27 \cdot 8(2 \cdot 3)$ \\
Sex (M:F) & $31: 19$ & $58: 42$ \\
Mean (SD) Apgar score: & $4 \cdot 4(2 \cdot 5)$ & $4 \cdot 8(2 \cdot 7)$ \\
$\quad$ At one minute & $7 \cdot 0(2 \cdot 0)$ & $7 \cdot 3(2 \cdot 2)$ \\
$\quad$ At five minutes & $31(62)$ & $57(57)$ \\
Hyaline membrane disease (No (\%)) & & $217(159)$ \\
Mean (SD) Admission arterial:fractional & $199(132)$ & $16(16)$ \\
$\quad$ inspiratory oxygen & $10(20)$ & $48(48)$ \\
Pneumothorax (No (\%)) & $19(38)$ & $74(74)$ \\
Patent ductus arteriosus (No (\%)) & $33(66)$ & \\
Survival (No (\%)) & &
\end{tabular}

Table 3 Differences in neonatal factors between cohorts 1 and 2. Values are mean (SD)

\begin{tabular}{llll}
\hline & Cohort 1 & Cohort 2 & $p$ Value \\
\hline Admission data: & & & \\
pH & $7 \cdot 25(0 \cdot 13)$ & $7 \cdot 30(0 \cdot 15)$ & $<0 \cdot 025$ \\
$\quad \begin{array}{l}\text { Temperature }\left({ }^{\circ} \mathrm{C}\right) \\
\text { Blood pressure }(\mathrm{mmHg})\end{array}$ & $35 \cdot 2(1 \cdot 2)$ & $35 \cdot 8(0.9)$ & $<0 \cdot 001$ \\
$\begin{array}{l}\text { Arterial carbon dioxide tension } \\
\quad(\mathrm{mmHg})\end{array}$ & $35(10)$ & $43(13)$ & $<0 \cdot 001$ \\
Blood pressure $(\mathrm{mmHg})$ & $40(10)$ & $44(7)$ & $<0.0025$ \\
\end{tabular}

Table 4 Incidence of periventricular haemorrhage and periventricular leucomalacia in cohorts 1 and 2. Values are No (\%)

\begin{tabular}{lccc}
\hline & $\begin{array}{c}\text { Cohort } 1 \\
(n=50)\end{array}$ & $\begin{array}{l}\text { Cohort } 2 \\
(n=100)\end{array}$ & $p$ Value \\
\hline Periventricular haemorrhage: & $30(60)$ & $36(36)$ & $<0 \cdot 001$ \\
$\quad$ Germinal layer & $7(14)$ & $8(8)$ & \\
Intraventricular & $15(30)$ & $20(20)$ & \\
Intracerebral & $8(16)$ & $8(8)$ & \\
& & & \\
Birth weight (g): & $8 / 12(67)$ & $9 / 21(43)$ & $<0 \cdot 025$ \\
$\quad$ 750 & $14 / 22(64)$ & $9 / 28(32)$ & \\
$751-1000$ & $8 / 16(50)$ & $18 / 51(35)$ & \\
1001-1250 & & & \\
& $6 / 8(75)$ & $4 / 11(36)$ & \\
Gestation (wks): & $10 / 12(83)$ & $7 / 13(54)$ & \\
$\quad \leqslant 24$ & $7 / 12(58)$ & $15 / 41(37)$ & \\
$25-26$ & $7 / 18(39)$ & $10 / 35(29)$ & \\
$27-28$ & & & \\
29 & $3 / 50(6)$ & $2 / 100(2)$ & \\
Periventricular leucomalacia: & $3 / 33(9)$ & $2 / 74(3)$ & \\
All infants & &
\end{tabular}

*All these infants weighed $\leqslant 1250 \mathrm{~g}$ at birth. periventricular haemorrhage suggest improvement in neonatal care.

The overall incidence of periventricular haemorrhage was significantly lower in cohort 2 compared with cohort $1(36 \% v 60 \%, \mathrm{p}<0 \cdot 001)$. Table 4 shows that the incidence of periventricular haemorrhage was lower across all birthweight and gestation subgroups, as was the incidence of periventricular leucomalacia.

The analysis to determine antecedents of periventricular haemorrhage identified many similar risk factors in both cohorts 1 and 2 . In both cohorts the only significant obstetric risk factor for periventricular haemorrhage was birth trauma $(p<0.005)$ as evidenced by severe bruising of the head. The significant intrapartum and neonatal antecedents of periventricular haemorrhage common to both cohorts included low admission arterial:fractional inspiratory oxygen ratio $(p<0.0125)$ and packed cell volume $(\mathrm{p}<0.025)$, hyaline membrane disease $(p<0.0125)$, hypercarbia $(p<0.0005)$, and hypoxaemia $(<0.005)$. Case control studies in subgroups of similar gestation (24-25, 26-27, and 28 weeks) and birth weight (655 (SD 82) g, $936(162) \mathrm{g}$, and $988(248) \mathrm{g}$ ) confirmed that the above antecedents were independent of the degree of prematurity. Neonatal factors that were significant antecedents of periventricular haemorrhage in cohort 1 but were no longer found to be significant in cohort 2 were mechanical ventilation, pneumothorax, administration of tubocurarine, low body temperature, and systemic hypotension. Analysis of the 16 infants who had a pneumothorax in cohort 2 showed that the eight infants who then developed periventricular haemorrhage were affected in a significantly different manner from those who did not develop haemorrhage. The effects of the pneumothorax were more pronounced in those with periventricular haemorrhage. These were higher peak arterial carbon dioxide tensions (86.5 (SD 37.7) v 54.6 (7.8) $\mathrm{mm} \mathrm{Hg}, \mathrm{p}<0.02)$, greater arterial carbon dioxide fluctuations $(55 \vee 28, \mathrm{p}<0.05)$, more profound hypoxia (arterial oxygen 25.1 (SD 11.9) v 43.8 (8.5) $\mathrm{mm} \mathrm{Hg}, \mathrm{p}<0 \cdot 05)$, greater arterial oxygen fluctuations $(108 v 45)$, more pronounced hypotension (26.8 (SD 8.1) v $38.9(8.4) \mathrm{mm} \mathrm{Hg}, \mathrm{p}<0.05)$, and greater blood pressure fluctuation (28 $v 24$, $\mathrm{p}<0.05)$. Similar results were obtained when analysing the 48 infants with patent ductus arteriosus and eight infants with pulmonary haemorrhage in cohort 2. Analysis of matched pairs comparing infants with intracerebral haemorrhage with those with no haemorrhage revealed that the significant antecedents of intracerebral haemorrhage in cohort 2 were acidosis at birth and on admission $(p<0.0125)$ and subsequent hypercarbia $(\mathrm{p}<0 \cdot 02)$ but not hypother- 
mia on admission, which was one of the antecedents of intracerebral haemorrhage in cohort 1 .

A multivariate discriminant analysis for the obstetric and neonatal antecedents of periventricular haemorrhage in cohort 2 showed that five factors correctly indicated the presence or absence of periventricular haemorrhage in $86 \%$ of infants. The most significant antecedents were severe bruising at birth (contributing 26\% to the discriminant function), hypercarbia (25\%), hypoxaemia $(24 \%)$, hyaline membrane disease $(15 \%)$, and short gestation $(11 \%)$. This contrasted with the results from cohort 1 where the three factors that correctly indicated the presence or absence of periventricular haemorrhage in $78 \%$ of infants were hyaline membrane disease $(43 \%)$, hypercarbia $(29 \%)$, and short gestation $(28 \%)$.

\section{Discussion}

The data analysis of antecedents of periventricular haemorrhage has revealed that birth trauma, reflected by severe bruising of the head at birth, hypercarbia, and hypoxaemia are the most significant risk factors for periventricular haemorrhage. Many other neonatal events such as mechanical ventilation, pneumothorax, pulmonary haemorrhage, persistent pulmonary hypertension, and patent ductus arteriosus were not significant. Nevertheless, these conditions can cause periventricular haemorrhage if they lead to appreciable or persistent hypercarbia and hypoxaemia and therefore fluctuations or increases in cerebral blood flow. The varying extent of the secondary effects on blood pressure and arterial blood gas tensions in individual infants caused by the above neonatal events probably explains why differing opinions have been reached in previous cerebral ultrasound studies $^{212-16}$ regarding the importance of these events as antecedents of periventricular haemorrhage. In our cohort the use of vasoactive drugs, including tubocurarine, pancuronium, dopamine, tolazoline, and indomethacin, during the vulnerable first four days of life does not increase the incidence of periventricular haemorrhage if every effort is made to maintain the infant's cardiorespiratory variables within normal limits.

Our analysis of obstetric events could not determine the importance of neonatal transport as $90 \%$ of cohorts 1 and 2 were inborn or antenatal steroids as less than $10 \%$ of cohorts 1 and 2 received betamethasone. Some published reports have suggested that prolonged labour was a significant antecedent of periventricular haemorrhage, ${ }^{17} 18$ while another study reached the opposite "conclusion. ${ }^{16}$ In both our cohorts prolonged labour whether defined as greater than six hours ${ }^{17}$ or greater than 12 hours $^{18}$ was not a significant antecedent unless accompanied by severe bruising of the head. The varying effects and degree of trauma associated with prolonged labour in preterm infants probably explain the conflicting opinions as to its importance in the pathogenesis of periventricular haemorrhage.

Defects in haemostasis, including coagulopathy, thrombocytopenia, and platelet dysfunction, have been associated with periventricular haemorrhage..$^{1920}$ We found, however, that the platelet count, prothrombin time, or partial thromboplastin concentrations on admission, and thrombocytopenia or disseminated intravascular coagulation in the first four days of life were not significant antecedents of periventricular haemorrhage. Contrary to a recent report, ${ }^{9}$ the use of fresh frozen plasma on day 1 was not associated with a lower incidence of periventricular haemorrhage in our cohort.

The incidence of periventricular haemorrhage in cohorts that included larger infants up to $1500 \mathrm{~g}$ birth weight (very low birth weight) has varied from $43-55 \% .12151621$ In the two studies that have data on infants less than $1000 \mathrm{~g}$ the incidence of periventricular haemorrhage ranged from 61$70 \% .^{215}$ In a recent review reporting pooled data from six centres the incidence of periventricular haemorrhage over a wide gestational range was reported as $77 \%(96 / 125)$ in preterm infants of $\leqslant 26$ weeks' gestation, $56 \%(102 / 182)$ in those of $27-28$ weeks' gestation, $37 \%(84 / 228)$ in those of $29-30$ weeks' gestation, $26 \%(62 / 239)$ in those of $31-32$ weeks' gestation, and $7 \%(11 / 150)$ in those of $\geqslant 33$ weeks' gestation. ${ }^{22}$ Compared with this pooled data, the incidence of periventricular haemorrhage at our hospital was significantly lower after introduction of guidelines aimed at reducing the frequency of factors that cause increases and fluctuations in cerebral blood flow. Our incidence of periventricular haemorrhage was $50 \%(13 / 26, \mathrm{p}<0.005)$ in preterm infants of $\leqslant 26$ weeks' gestation, $36 \%$ $(20 / 56, p<0 \cdot 005)$ in those of $27-28$ weeks' gestation, $16 \%(11 / 68, p<0.0025)$ in those of $29-30$ weeks' gestation, $5 \%(6 / 121, p<0.0005)$ in those of $31-32$ weeks' gestation, and $2 \%(2 / 100, p<0.05)$ in those of $\geqslant 33$ weeks' gestation. Multivariate discriminant analysis confirmed that adherence to strict guidelines resulted in a change of weighting of antecedent factors of periventricular haemorrhage, so that in cohort 2 hyaline membrane disease and short gestation were less powerful discriminants than severe bruising at birth, hypercarbia, and hypoxaemia.

Recent reports have claimed significant reductions in periventricular haemorrhage after introduction of treatment with drugs. ${ }^{3-9}$ Two studies of 
significant reduction in incidence of periventricular haemorrhage in very low birthweight infants to $16 \%{ }^{7}$ and $13 \%{ }^{3}$ after use of vitamin $E$ and phenobarbitone are difficult to interpret as the infants were not scanned before enrolment into placebo or treatment groups. In a cohort of similar gestation and birth weight to these reports ${ }^{37}$ our incidence of periventricular haemorrhage was $24 \%(47 / 196)$. In studies where infants were scanned before enrolment into placebo or treatment groups the incidence of periventricular haemorrhage in treated groups was $48 \%(10 / 21)$ with phenobarbital, ${ }^{4} 23 \%(10 / 43)$ with ethamsylate, ${ }^{5} 43 \%(9 / 21)$ with vitamin $E,{ }^{6} 36 \%$ $(5 / 14)$ with pancuronium, ${ }^{8}$ and $14 \%(5 / 36)$ with fresh frozen plasma. ${ }^{9}$ Our incidence of periventricular haemorrhage without use of treatment with drugs or fresh frozen plasma in identical groups to those reported ${ }^{4-689}$ was equally low after the introduction of strict guidelines for neonatal care, being $17 \%$ (50/289), 24\% (44/183), 20\% (50/255), $22 \%(40 / 183)$. and $20 \%(47 / 241)$, respectively.

As neonatal practices change rapidly as more experience accumulates in the treatment of very and extremely low birthweight infants it is important that the effects of these changes are not overlooked when a prophylactic drug for prevention of periventricular haemorrhage is introduced. Our risk factor analysis showed the importance of matching groups for all known antecedents of periventricular haemorrhage and for disturbances of blood gases and blood pressure and not only for birth weight and gestation before any conclusions regarding drug efficacy can be reached. As the neurodevelopmental outcome of extremely preterm or low birthweight infants is closely related to the degree of periventricular haemorrhage and periventricular leucomalacia ${ }^{23-25}$ the reduction of their incidence whether by changes in neonatal management or by treatment with drugs should lead to decreased long term disability in the more recent survivors.

\section{References}

${ }^{1}$ Szymonowicz W, Yu VYH, Wilson FE. Antecedents of periventricular haemorrhage in infants weighing $1250 \mathrm{~g}$ or less at birth. Arch Dis Child 1984;59:13-7.

2 Thorburn RJ, Lipscomb AP, Stewart AL, Reynolds EOR, Hope PL. Timing and antecedents of periventricular haemorrhage and of cerebral atrophy in very preterm infants. Early Hum Dev 1982;7:221-38.

3 Donn SM, Roloff DW, Goldstein GW. Prevention of intraventricular haemorrhage in preterm infants by phenobarbitone-a controlled trial. Lancet 1981;ii:215-7.

${ }^{4}$ Bedard MP, Shankaran S, Slovis TL, Pantoja A, Dayal B, Poland RL. Effect of prophylactic phenobarbital on intraventricular hemorrhage in high-risk infants. Pediatrics 1984;73:435-9.

5 Cooke RWI, Morgan MEI. Prophylactic ethamsylate for periventricular haemorrhage. Arch Dis Child 1984;59:82-3.

6 Chiswick ML, Johnson M, Woodhall C, et al. Protective effect of vitamin $\mathrm{E}$ (DL-alpha-tocopherol) against intraventricular haemorrhage in premature babies. $\mathrm{Br}$ Med $J$ 1983;287:81-4.

${ }^{7}$ Speer ME, Blifeld C, Rudolph AJ, Chadda P, Holbein MEB, Hittner HM. Intraventricular hemorrhage and vitamin $E$ in the very low-birth-weight infant: evidence for efficacy of early intramuscular vitamin E administration. Pediatrics 1984;74: 1107-12.

${ }^{8}$ Perlman JM, Goodman S, Kreusser KL, Volpe JJ. Reduction in intraventricular hemorrhage by elimination of fluctuating cerebral blood-flow velocity in preterm infants with respiratory distress syndrome. $N$ Engl J Med 1985;312:1353-7.

9 Beverley DW, Pitts-Tucker TJ, Congdon PJ, Arthur RJ, Tate G. Prevention of intraventricular haemorrhage by fresh frozen plasma. Arch Dis Child 1985;60:710-3.

10 Szymonowicz W, Yu VYH. Timing and evolution of periventricular haemorrhage in infants weighing $1250 \mathrm{~g}$ or less at birth. Arch Dis Child 1984;59:7-12.

11 Szymonowicz W, Schafler K, Cussen LJ, Yu VYH. Ultrasound and necropsy study of periventricular haemorrhage in preterm infants. Arch Dis Child 1984;59:637-42.

12 Cooke RWI. Factors associated with periventricular haemorrhage in very low birthweight infants. Arch Dis Child 1981;56:425-31.

13 Hill A, Perlman JM, Volpe JJ. Relationship of pneumothorax to occurrence of intraventricular hemorrhage in the premature newborn. Pediatrics 1982;69:144-9.

14 Dolfin T, Skidmore MB, Fong KW, Hoskins EM, Shennan AT. Incidence, severity and timing of subependymal and intraventricular hemorrhages in preterm infants born in a perinatal unit as detected by serial real-time ultrasound. Pediatrics 1983;71:541-6.

15 Hawgood S, Spong J, Yu VYH. Intraventricular hemorrhagethe incidence and outcome in a population of very low birthweight infants. Am J Dis Child 1984;138:136-9.

16 Beverley DW, Chance GW, Coates CF. Intraventricular haemorrhage-timing of occurrence and relationship to perinatal events. Br J Obstet Gynaecol 1984;91:1007-13.

17 Horbar JD, Pasnick M, McAuliffe TL, Lucey JF. Obstetric events and risk of periventricular hemorrhage in premature infants. Am J Dis Child 1983;137:678-81.

18 Meidell R, Merinelli P, Pettett G. Perinatal factors associated with early-onset intracranial hemorrhage in premature infants. A prospective study. Am J Dis Child 1985;139:160-3.

19 Setzer ES, Webb IB, Wassenaar JW, Reeder JD, Mehta PS, Eitzman DV. Platelet dysfunction and coagulopathy in intraventricular hemorrhage in the premature infant. $J$ Pediatr 1982;4:599-605.

${ }^{20}$ McDonald MM, Johnson ML, Rumack CM, et al. Role of coagulopathy in newborn intracranial hemorrhage. Pediatrics 1984;74:26-31.

${ }^{21}$ Papile L-A, Burstein J, Burstein R, Koffler H. Incidence and evolution of subependymal and intraventricular hemorrhage: a study of infants with birth weights less than $1500 \mathrm{gm}$. J Pediatr 1978;92:529-34.

22 Allan WC, Philip AGS. Neonatal cerebral pathology diagnosed by ultrasound. Clin Perinatol 1985;12:195-218.

23 DeVries LS, Dubowitz LMS, Dubowitz V, et al. Predictive value of cranial ultrasound in the newborn baby: a reappraisal. Lancet 1985;i:137-40.

${ }^{24}$ Cooke RWI. Neonatal cranial ultrasound and neurological development at follow-up. Lancet 1985; ii:494-5.

${ }^{25}$ Szymonowicz W, Yu VYH, Bajuk B, Astbury J. Neurodevelopmental outcome of periventricular haemorrhage and leukomalacia in infants 1250 grams or less at birth. Early Hum Dev. (In press.)

Correspondence to Dr W Szymonowicz, Department of Paediatrics, Queen Victoria Medical Centre, 172 Lonsdale Street, Melbourne, Victoria 3000 , Australia.

Received 26 March 1986 